\title{
Stability of Electrical Resistance of Isotropic Conductive Adhesives within Mechanical Stress
}

\author{
Aleš Duraj ${ }^{1}$, Pavel Mach ${ }^{1}$
}

\author{
${ }^{1}$ Department of Electrotechnology, Faculty of Electrical Engineering \\ Czech Technical University, Prague 6, 166 27, Czech Republic \\ E-mail: duraja $@$ centrum.cz, $\operatorname{mach}(a$ fel.cvut.cz
}

\begin{abstract}
This work is focused on investigation of influence of dynamic mechanical load (bending of testing boards) on resistance of the adhesive joints. The load has been induced by a definite deflection of testing boards (fiberglass laminated PCB assembled with $1206 \mathrm{SMD}$ resistors). There were used four different types of isotropic electrically conductive adhesives (two types of one-component, one type of two-component adhesive and one type of conductive lacquer). The frequency of one cycle per second $(1 \mathrm{~Hz})$ has been used for generation of the dynamic load ( 2000 cycles of bend have been applied). For the analysis of adhesive joint resistance has been used precision LCR meter HP 4284A with continual measuring software (WEE Pro v6.0). The dynamic load has caused changes of basic electrical parameters of the bonds The more of deflections has been applied the more changes of parameters have been found. Nevertheless increasing of joint resistance is not linear and it is not same for all tested adhesives - initial rising of resistance is in most cases higher than changes after few cycles. From our experiment it is evident that for low deflection of testing board there are both of permanent and also elastic deformations in adhesive joints (graphs of joint resistance have not continual rising trend).
\end{abstract}

\section{INTRODUCTION}

Isotropic and anisotropic electrically conductive adhesives (ICAs and ACAs) are alternative materials for substitution of common used tin-lead solders in electronic assembly. Electrically conductive adhesives (ECAs) were developed especially for joining in applications, where the use of high temperature (necessary for soldering) is impossible. Basic material of ICAs is usually epoxy or acrylic resin (insulating material) and electrically conductive filler (Ag flakes or balls). Electrically conductive adhesives, especially ACAs and ACFs are potential materials for the bonding of surface mounted components and for some special applications, e.g. flip-chip assembly, chip-onfilm (COF), chip-on-glass (COG) or for flexible circuit assembly applications (chip-on-flex). ACFs are also extensively used for connection between PCB and LCD or liquid crystal module (LCM). Quality of these adhesive joints is evaluated according of their electrical and mechanical properties. Measurement of these parameters is also important for long-time reliability of adhesive joints. Often HAST (highly accelerated stress tests) are used. Results of examination of adhesive bonds under dynamic mechanical load are presented in this paper.

\section{APPLIED MATERIALS AND TESTS}

Experiment involves four different types of isotropic electrically conductive adhesives: two types of one-component, one type of two-component adhesive and one type of electrically conductive lacquer. In Tab. 1 there are shown specifications of these materials.

Tab. 1. Tested electrically conductive adhesives

\begin{tabular}{|l|l|}
\hline Type & Properties \\
\hline \hline $\begin{array}{l}\text { Amepox AX 20 } \\
\text { (ECO Solder) } \\
\text { (one-component adhesive) }\end{array}$ & $\begin{array}{l}\text { bisphenol epoxy resin } \\
+ \text { formulated } \mathrm{BF}_{3} \\
75 \% \mathrm{Ag} \text { flakes }\end{array}$ \\
\hline $\begin{array}{l}\text { Amepox ER 55 } \\
\text { (one-component adhesive) }\end{array}$ & $\begin{array}{l}\text { bisphenol epoxy resin } \\
+ \text { butyl glycidyl ether } \\
75 \% \mathrm{Ag} \text { flakes }\end{array}$ \\
\hline $\begin{array}{l}\text { Amepox AX 656S } \\
\text { (two-component adhesive) }\end{array}$ & $\begin{array}{l}\text { bisphenol epoxy resin } \\
+ \text { formulated polyamine } \\
80 \% \mathrm{Ag} \text { flakes }\end{array}$ \\
\hline $\begin{array}{l}\text { Amepox ER 48 } \\
\text { (conductive lacquer) }\end{array}$ & $\begin{array}{l}\text { acrylic resin } \\
+ \text { thinners } \\
47 \% \mathrm{Ag} \text { flakes }\end{array}$ \\
\hline
\end{tabular}

Adhesive bonds have been fabricated by mounting of SMD resistors (1206 0R0 - from Microtech $\mathrm{GmbH}$ ) with special contacts finish for adhesive connetions - shown on Fig. 1. Basic material of testing board (PCB) is common used fibreglass laminate (FR4) and material of conductive paths is plated $\mathrm{Cu} 35 \mu \mathrm{m}$ foil. This testing board is shown on Fig. 2. Parameters of this board are:

\begin{tabular}{|l|l|}
\hline Length: $1=80 \mathrm{~mm}$ & Width: $\mathrm{w}=25 \mathrm{~mm}$ \\
\hline Thickness: $\mathbf{t}=1,5 \mathrm{~mm}$ & Young's $\mathrm{m} .: \mathrm{E}=22 \mathrm{GPa}$ \\
\hline
\end{tabular}

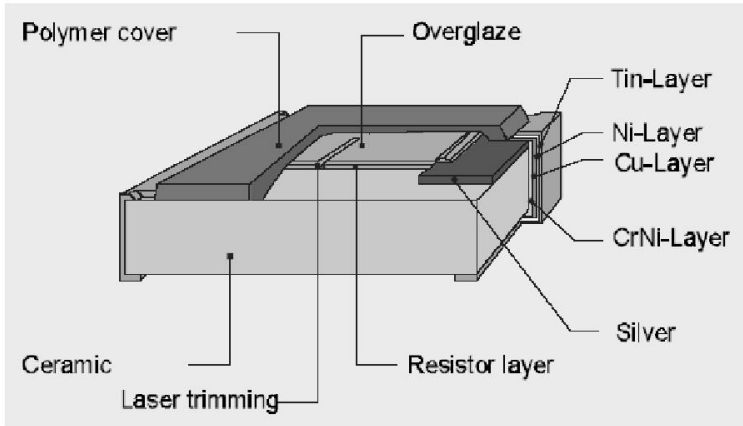

Fig. 1. SMD resistor with lead-free contacts finish used for testing of influence of dynamic mechanical load on adhesive joints 


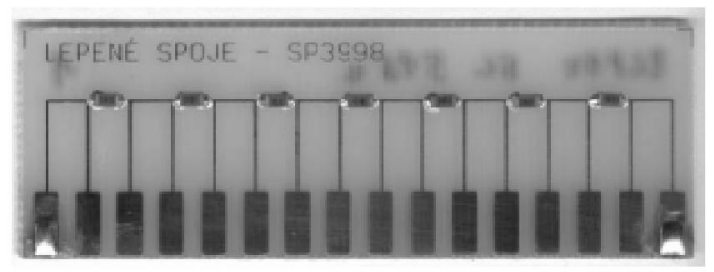

Fig. 2. Testing board assembled with 7 SMD resistors

For application of dynamic mechanical load a special fixture has been realized. The fixture is usable for compassing of 7 test boards together - shown on Fig. 3.

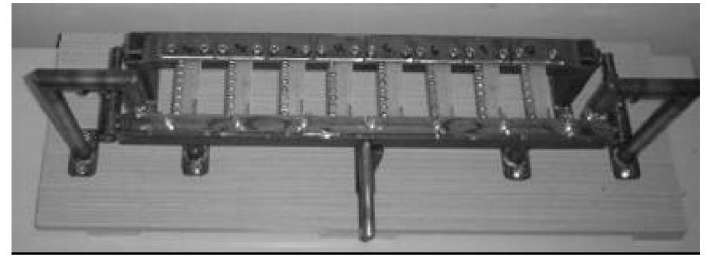

Fig. 3. Fixing for application of dynamic mechanical load.

The adhesive bonds are loaded with different load according to their location on the testing board and its deflection. Schematic principle of the testing is shown on Fig. 4. The more SMD resistors are closer to fixation of board (left side on figure) the more joints are strained with tensile and shear forces. Shear force is dominant for this type of bend. There were chosen two values of deflection for a comparison of influence of dynamic mechanical load on joint resistance:
a) $\pm 3 \mathrm{~mm}$
b) $\pm 4,5 \mathrm{~mm}$

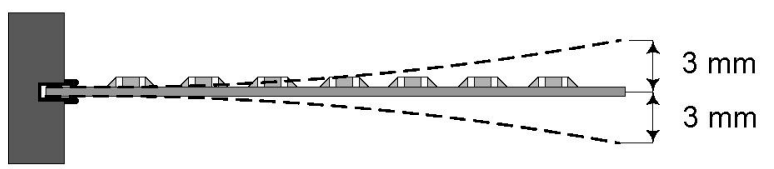

Fig. 3. Principle of dynamic mechanical load.

We appear from differential evaluation for flexural line for a mathematical calculation of bend straining of testing board. Scheme of evaluation of flexure is shown on Fig. 4.

$$
\frac{d^{2} y}{d x^{2}} \cdot\left[1+\left(\frac{d y}{d x}\right)^{2}\right]^{-\frac{3}{2}}=-\frac{M_{O}}{E \cdot I_{Z}}
$$

E... Young's modulus, $M_{\odot} \ldots$ bending moment $\mathrm{I}_{\mathrm{Z}} \ldots$ quadratic moment

For rectangle:

$$
I_{Z}=\frac{1}{12} w t^{3}
$$

For a small deflection:

$$
\left(\frac{d y}{d x}\right)^{2}=0
$$

then;

$$
\frac{d^{2} y}{d x^{2}}=-\frac{M_{O}(x)}{E \cdot I_{Z}}
$$

Initial conditions: $\mathrm{x}=0 \rightarrow \mathrm{y}=0, \mathrm{dy} / \mathrm{dx}=0$

For a deflection is valid:

$$
y_{x}=-\frac{F}{E \cdot I_{Z}} \cdot\left(\frac{x^{3}}{6}-\frac{x^{2}}{2} l\right)
$$

If $\mathrm{y}=1$ (length of board) than:

$$
y_{l}=\frac{1}{3} \cdot \frac{F \cdot l^{3}}{E \cdot I_{z}}
$$

Force on the end of the board (needed for a bend):

$$
F=3 \frac{y_{l} \cdot E \cdot \frac{w t^{3}}{12}}{l^{3}}
$$

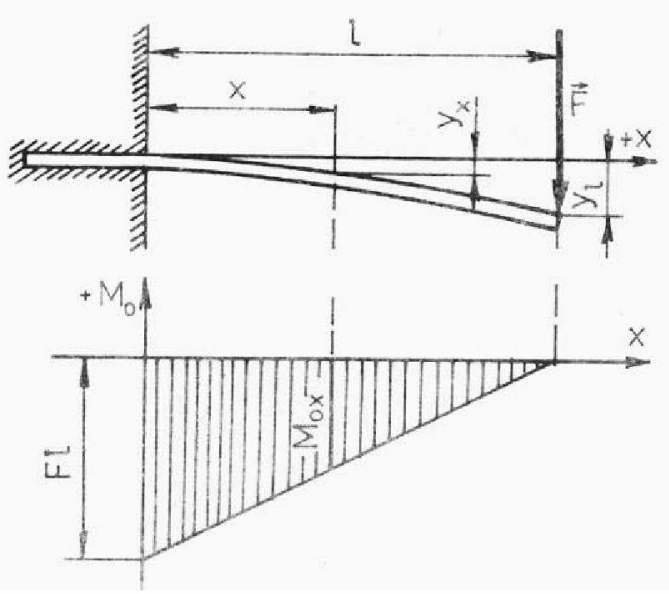

Fig. 4. Scheme of the evaluation of flexure (fixed beam).

\section{MEASUREMENT}

Influence of dynamic mechanical load has been analyzed with measurement of electrical resistance. Resistance of the joints has been continually measured with LCR meter HP 4284A and WEE Pro v6.0 software. Conditions of measurement:

- measurement of SMD + 2 joints

- $\quad \mathrm{R}_{\mathrm{ST}}$ - resistance of SMD + 2 joints

- measurement of whole testing board (7 SMD)

- $\quad \mathrm{R}_{\mathrm{wb}}$ - resistance $7 \mathrm{SMD}+14$ joints

- measuring voltage: $50 \mathrm{mV}, \mathbf{f}=1 \mathrm{kHz}$

Single SMD connections on testing boards have been measured before dynamic mechanical load. There have been applied 2000 cycles of bends (approximately $1 \mathrm{cycle} / \mathrm{sec}$ ) and every 100 cycles there has been accomplished a measurement of electrical resistance of whole assembled testing board. After 2000 cycles of mechanical load the single SMD connections has been re-measured and analyzed. 


\section{RESULTS and DISCUSSION}

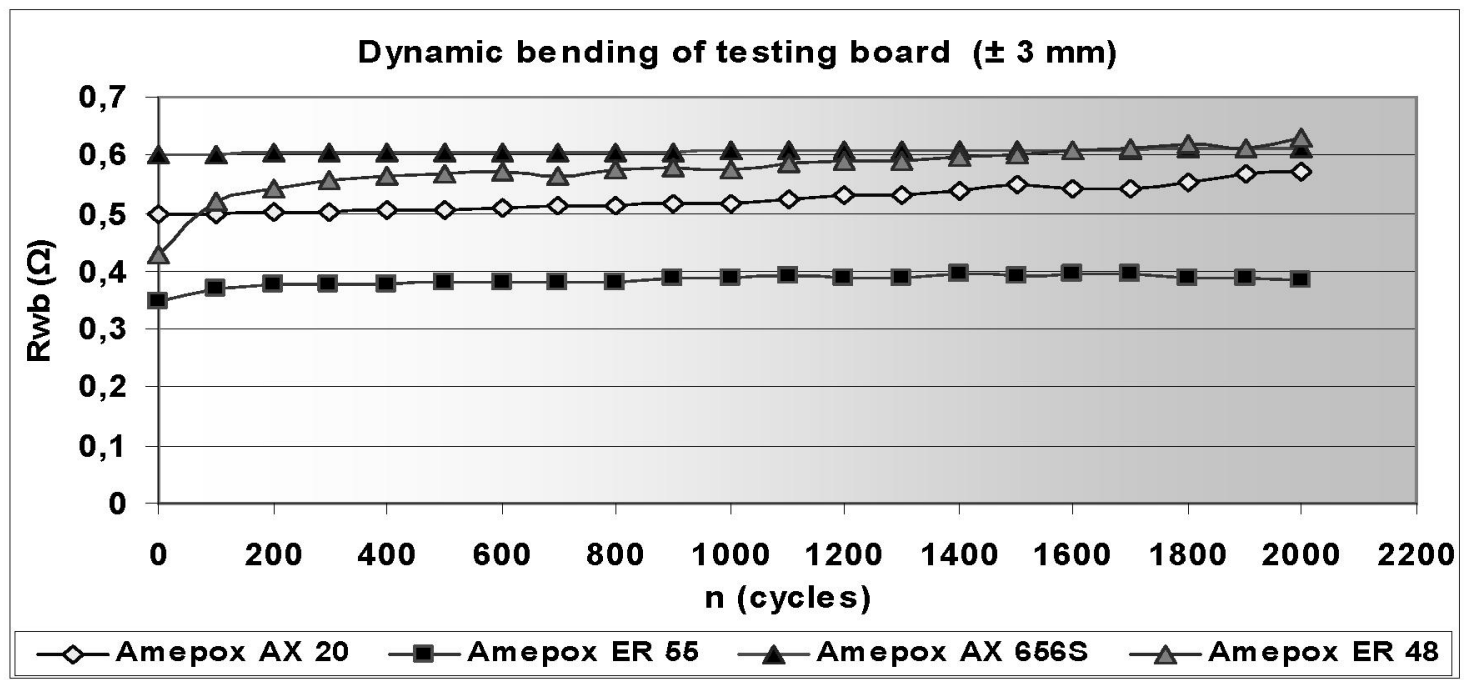

Fig. 5. Influence of dynamic mechanical load on resistance of adhesive joints (deflection $\pm 3 \mathrm{~mm}$ ).

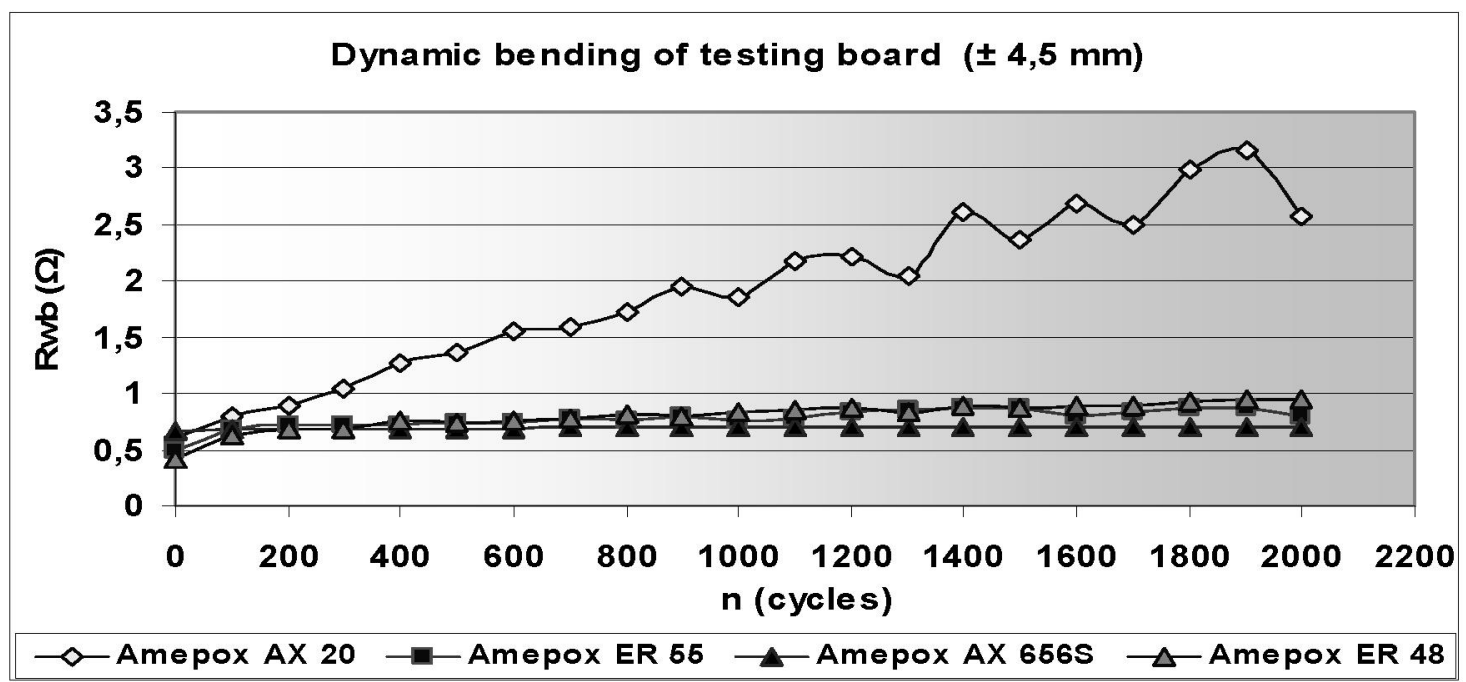

Fig. 6. Influence of dynamic mechanical load on resistance of adhesive joints (deflection $\pm 4,5 \mathrm{~mm}$ ).

Four different types of isotropic electrically conductive adhesives have been strained with dynamic mechanical load (dynamic bending of assembled testing boards) and the joint resistance has been measured with four-point method. In selected types there is a type AX 20 which is new exemplar of Amepox company products. This type is also called Eco Solder which can be used as a substitution of tinlead solders. For our tests we also select one type of conductive lacquer ER 48 which is mainly specified for repairing of damaged conductive paths on printed circuit boards. This experiment try to find out if is it possible to use this material for connections in surface mount technology (SMT). Results from measurement of influence of dynamic mechanical load on resistance of adhesive joints are shown on Fig. 5 and Fig. 6. From graphs on Fig. 5 and from Tab. 2 is evident that low deflection of testing board $( \pm 3 \mathrm{~mm}$ ) have not a radical effect on increasing of joint resistance. The highest increase of resistance at low deflections has been found on conductive lacquer (about $+40 \%$ ). Nevertheless initial values of resistance are very low in comparison with other tested materials. Also measurement of nonlinearity of voltage-current characteristics from another experiments demonstrate that this conductive lacquer have very good electrical parameters. Nevertheless mechanical strength and resistance against mechanical load, which is very considerable too, is not high enough. So this material is not possible to use for direct connection of SMD to printed circuit boards.

Tab. 2. Shift of joint resistance after 2000 cycles of mechanical load of testing boards

\begin{tabular}{|l|c|c|c|}
\hline Rwb [m $\Omega]$ & Initial & $2000 \mathrm{c}$ & shift \\
\hline AX20 $\pm 3 \mathrm{~mm}$ & 498 & 546 & $+9,4 \%$ \\
\hline AX20 $\pm 4.5 \mathrm{~mm}$ & 608 & 2047 & $+236 \%$ \\
\hline ER55 $\pm 3 \mathrm{~mm}$ & 356 & 379 & $+9,5 \%$ \\
\hline ER55 $\pm 4.5 \mathrm{~mm}$ & 495 & 978 & $+97,6 \%$ \\
\hline AX656S $\pm 3 \mathrm{~mm}$ & 603 & 618 & $+2,5 \%$ \\
\hline AX656S $\pm 4.5 \mathrm{~mm}$ & 673 & 703 & $+4,5 \%$ \\
\hline ER48 $\pm 3 \mathrm{~mm}$ & 419 & 587 & $+40,1 \%$ \\
\hline ER48 $\pm 4.5 \mathrm{~mm}$ & 410 & 735 & $+79,3 \%$ \\
\hline
\end{tabular}


New type of conductive adhesive AX 20 is resistive enough against small deflections of assembled boards but greater dynamic mechanical load has radical effect on increasing of electrical resistance. From our experiment we have found that this conductive adhesive is least resistant to mechanical straining.

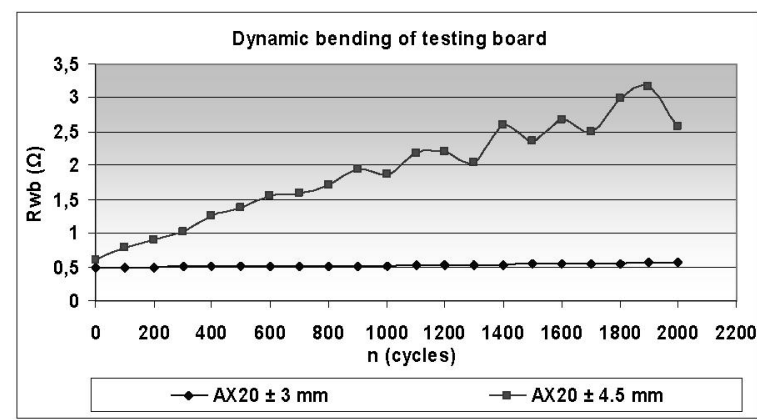

Fig. 7. Influence of mechanical load on joint resistance (AX 20).

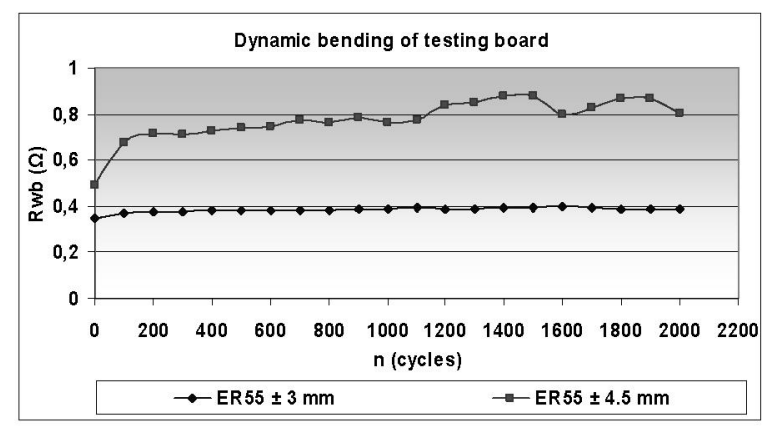

Fig. 8. Influence of mechanical load on joint resistance (ER 55).

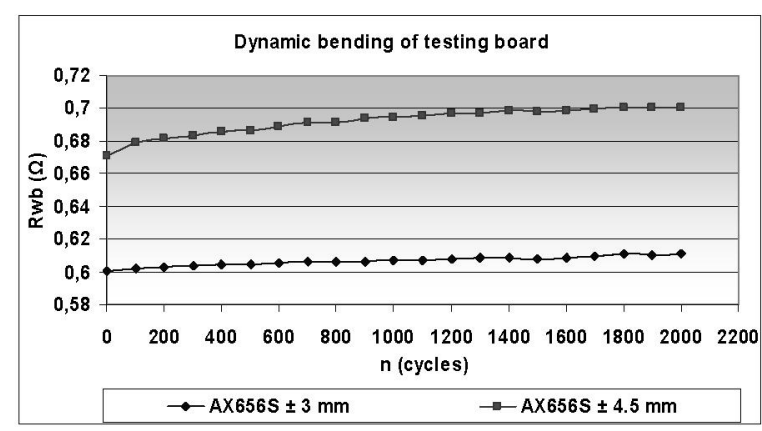

Fig. 9. Influence of mechanical load on joint resistance (AX 656S).

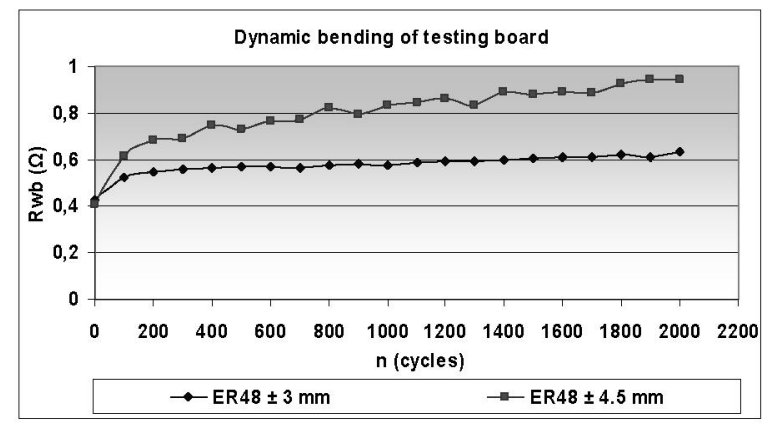

Fig. 10. Influence of mechanical load on joint resistance (ER 48).

\section{CONCLUSIONS}

From graphs shown on Fig. 7 to Fig. 10 there is possible to say that dynamic mechanical load generate not only permanent and also elastic deformations in adhesive joints. Graphs of joint resistance have not continual rising trend so in the structure of adhesives are also reversible changes. Increasing of joint resistance is not the same for all tested materials - AX 20 have almost linear curve of resistance during whole range of number of cycles whereas electrical resistance of ER 55 rapidly increase within first 200 cycles. That means that permanent deformations are dominant in structure of this material. Electrical resistance of $\mathrm{AX} 656 \mathrm{~S}$ (two-component adhesive) increase only a few of percent. Additional hardener in this adhesive probably makes structure more solid and more durable to mechanical load. Joints realized with conductive lacquer ER 48 have low initial values of electrical resistance but stability during mechanical straining is poor even for small deflections of testing board. So this adhesive is not suitable for direct assembly of SMDs.

This research was supported by grant: Czech Republic - MSM No.6840770021 - Diagnostic of Materials

\section{REFERENCES}

[1] Blackwell, G.R. "The Electronic Packaging Handbook", New York: CRC Press/IEEE 2000, Conductive adhesives for surface mounting - pp.346369 , Lead-free solders - pp.461-473

[2] Collins, A., "Low Stress, High Strength Isotropic Conductive Film Adhesive for Large Are Bonding of Thermally Mismatched Substrates", Proceedings of $15^{\text {th }}$ EMPC 2005, Brugge, Belgium

[3] Y.C. Chan, D.Y. Luk, "Effects of bonding parameters on the reliability performance of anisotropic conductive adhesive interconnects for flipchip-on-flex packages assembly, II. Different bonding pressure", Microelectronics Reliability, Vol. 42, Issue 8, August 2002, pp. 1195-1204.

[4] Hans de Vries, J. "Failure Mechanism of ACA's Interconnections in Flip Chip ICs on Flexible Substrates", IEEE Transactions on Components and Packaging Technologies, vol. 27, March 2004

[5] Chuks N. Oguibe et al. "Conduction mechanism in anisotropic conducting adhesive assembly", IEEE Transactions on components, packaging and manufacturing technology, vol.21,No.2, pp.235-241, June 1998

[6] Mach, P., Krejzlík, V., "Properties of electrically conductive adhesive joints under mechanical load", $8^{\text {th }}$ SIITME. ITEC Cluj-Napoca. Romania. 2002, pp. 5- 9

[7] Duraj,A.,Mach,P.,"Influence of Different Types of Surfaces of Pads on Mechanical Properties of ECAs and Solders", Proc $15^{\text {th }}$ European Microelectronics and Packaging Conference \& Exhibition, Brugge, Belgium, June 2005, pp. 604-607. 